\title{
The business of making vaccines
}

\author{
Cormac Sheridan
}

With a growing need for better and more plentiful vaccines, traditional vaccine companies are responding by
increasing manufacturing capacity, the biotech industry, with innovative products. Both are surely needed.

The landscape in vaccine manufacturing has changed radically over the past 30 years. In 1967, over a dozen licensed vaccine manufacturers operated in the United States alone. This number has since collapsed through mergers and exits to barely a handful ${ }^{1}$. Low profit margins, the introduction in 1980 of good manufacturing practices (GMP) to vaccine production (which caused manufacturing costs to skyrocket) and the specter of liability all contributed to the contraction in the industry. Five companies-Chiron (Emeryville, CA, USA), GlaxoSmithKline (Brentford, UK), Merck (Whitehouse Station, NJ, USA), Sanofi Pasteur (Lyon, France) and Wyeth (Madison, NJ, USA) - account for close to $90 \%$ of the influenza vaccine supply in the world (Fig. 1). Now the landscape may be about to change again, as attention is riveted on vaccine supplies, in anticipation of a possible influenza pandemic.

\section{Bouncing back}

The price for a vaccine has jumped from a few dollars for a course of routine pediatric vaccines in the 1980 s to over $\$ 200$ for Wyeth's blockbuster vaccine Prevnar (pneumococcal 7 -valent conjugate vaccine) against meningitis and bloodstream infections. Some say Prevnar has transformed the vaccine business almost overnight. Although vaccine sales on the whole have risen rather modestly over the past 20 years, from $\$ 2$ billion in 1982 to only over $\$ 8$ billion today-a pittance compared with the drug market as a whole-recent projections show the vaccine market growing at double digits annually, which outpaces other infectious disease sectors ${ }^{2}$. The new crop of vaccines, like Merck's Gardasil (a recombinant vaccine comprising human papilloma virus, $\mathrm{HPV}$ ) subtypes $6,11,16$ and 18), which was recently shown to be $100 \%$ effective in

Cormac Sheridan is a writer based in Dublin.

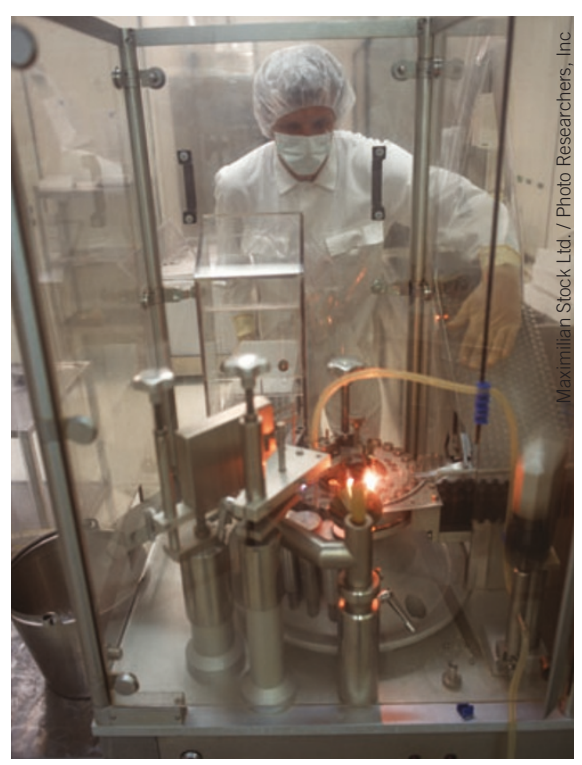

preventing cervical cancer, is projected to bring in $\$ 750$ million to over $\$ 1$ billion annually.

Keeping up with the demand for new vaccines, let alone responding to possible epidemics, natural or man-made, could well overwhelm the already stretched-to-capacity manufacturers of these prophylactics. Although vaccine manufacturers are loath to discuss capacity right now in the highly politicized environment created by the fear of a influenza pandemic, a look at their activity suggests that they are concerned about capacity and committed to increasing it. Each of the top five vaccine-producing companies has increased capacity either through acquisitions or through building facilities from scratch (Table 1).

The flurry of big pharma merger and acquisition activity this fall, which centered on targets with large influenza vaccine franchises, underlines the extent to which vaccines are now considered a worthwhile investment opportunity by the industry's biggest guns. GlaxoSmithKline's \$1.4 billion bid for ID Biomedical, of Vancouver, Canada, and Basel-based Novartis's attempt to become the outright owner of Chiron are evidence of an ongoing revival of this previously viewed low-profit, Cinderella sector.

\section{Under the regulatory microscope}

Several factors have kept new companies from entering the fray, and might continue to do so going forward, even with the optimistic market projections. The high level of capital expenditure involved in vaccine production, combined with its complexity (Table 2) have enabled the larger players to maintain their dominance. Many vaccines are low-margin products, so large economies of scale, combined with deep production experience have proved effective barriers to entry. "Every single step in the manufacture of a vaccine is extremely challenging," says Philippe Monteyne, vice president of worldwide cervical cancer vaccine Cervarix operations with GSK Biologicals. However, although many production methods, such as egg-based production of influenza vaccines, are decades old, they are constantly being refined to keep pace with developing regulatory requirements. "We can't say we are making vaccines like we were doing even five or ten years ago," he says.

The US Food and Drug Administration's (FDA's) Center for Biologics Evaluation and Research (CBER), which regulates the production of vaccines, is steering all companies falling within its remit toward a modern systems-based approach to quality management. Its officials have been critical of vaccine producers, in particular, for failing to put sufficient controls in place throughout the manufacturing process to allow for full investigation of product failures. According to Gordon Richman, vice president and general counsel at EduQuest, (Hyattstown, MD, USA), a consultancy that advises on 
compliance, GMP guidelines previously allowed deviations to be viewed in isolation, but the current approach is more holistic. "In this environment, every problem needs to be looked at as a quality system failure."

Influenza vaccine producers have come under increased scrutiny after the debacle at Chiron's Fluvirin (trivalent inactivated influenza virus vaccine) production plant in Speke, England, last year. From the beginning of this year, the FDA has increased its schedule of inspections from every two years to an annual audit, and it is currently considering extending this regime to producers of other "medically necessary products," particularly those produced offshore, according to a presentation by Mary Malarkey, director of the CBER's Office of Compliance and Biologics Quality, at the 10th Annual GMP by the Sea Conference, held in Cambridge, Maryland, in August.

\section{Opportunity knocks}

Although the five big players dominate the industry at present, their hegemony is being challenged from below by innovative biotech companies working on creating new and more robust delivery systems (Box 1) and, as demonstrated by the recent Novartis bid, from within their own peer group also.

This dynamic is easily explained. The vaccines market enjoyed a compound annual growth rate of over 25\% between 1999 and 2003, according to John Savopoulos, head of the infectious disease team at London-based market analysts Datamonitor. Estimated global revenues rose from $\$ 3.5$ million to $\$ 8.8$ billion during this time, and double-digit sales growth is set to continue for the foreseeable future. "That's why the market is attractive, as there are not many areas in healthcare that offer that kind of growth," he claims. Precise forecasting is difficult, he says, as a substantial level of vaccine purchasing is driven by public policy recommendations, whose implementation is not always predictable. Nevertheless, several drivers are propelling the market. Demand for influenza vaccination, which must be redesigned each year to match the curent strain, continues to rise. In

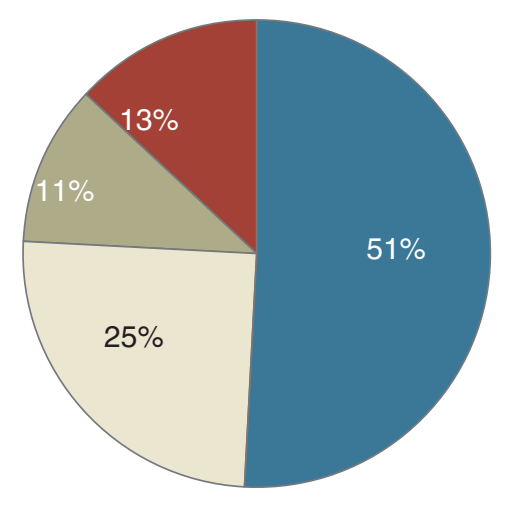

Others GSK Chiron Sanofi Pasteur

Figure 1 Estimated current worldwide flu vaccine manufacturing capacity (300 million doses). Source: GSK, Brentford, UK. http://www.gsk.com/ financial/presentations/vaccines2005/Flu.pdf

the United States, the Atlanta-based Centers for Disease Control and Prevention's (CDC) Healthy People 2010 initiative, which aims to boost infectious disease immunization

\section{Table 1 Vaccine franchises and increases to manufacturing capacity by the top five vaccine producers}

\begin{tabular}{ll} 
Company & Major vaccine programs \\
\hline Chiron & $\begin{array}{l}\text { Flu, meningococcal meningitis, Haemophilus } \\
\text { influenzae type } 1 \text { b meningitis, diphtheria, } \\
\text { measles, mumps, whooping cough, pneumo- } \\
\text { coccal disease, polio, rubella, tetanus, rabies, } \\
\text { yellow fever, cholera, tick-borne encephalitis }\end{array}$ \\
GlaxoSmithKline & $\begin{array}{l}\text { Diphtheria, tetanus, whopping cough, hepatitis } \\
\text { A and B, flu, polio (Sabin), measles, mumps, } \\
\text { rubella, meningococcal meningitis, smallpox, } \\
\text { rotavirus (approved outside the US) }\end{array}$
\end{tabular}
rotavirus (approved outside the US)

Merck

Haemophilus influenzae type $b$, hepatitis $A$ hepatitis $B$, measles, mumps, rubella pneumococcal disease, chicken pox

Sanofi-Pasteur Whooping cough, diphtheria, Haemoophilus influenza type $1 \mathrm{~b}$, meningococcal meningitis, tetanus, tuberculosis, typhoid fever, cholera, yellow fever, mumps, polio, measles, rubella, flu, hepatitis $A$ and $B$, rabies, chicken pox, Japanese encephalitis
Development pipeline

Meningococcal disease (conjugate), hepatitis $C$ virus (subunit), HIV (subunit), flu (made in cell culture), meningitis (membrane protein subunit)

HPV (virus-like particle in baculovirus), rotavi rus (live human, attenuated, for US), pneumo coccal (conjugate), flu (made in cell culture), meningitis (conjugate, trivalent), Dengue fever (attenuated), herpes (subunit), HIV (subunit) hepatitis $\mathrm{E}$ (virus-like particle)

HPV (virus-like particle in yeast), rotavirus (live human/bovine attenuated), shingles (live attenuated), flu (live, attenuated, nasal), tuberculosis (subunit), HIV (live recombinant)

AIDS (canarypox, subunit vaccine, and live recombinant), Dengue (live attenuated, tetravalent), flu (inactivated), typhoid (conjugate), respiratory syncytial virus (RSV, live, attenuated), pneumococcal disease (conjugated 11 valent), meningitis (conjugate, tetravalent)
Increases to manufacturing

Acquired Italy-based Scalvo (1992)

Acquired Germany-based Behring (1998)

Acquired UK-based PowerJect (2003)

$\$ 97$ million to remediate Liverpool plant

Acquired ID Biomedical Corp. in 2005 for eggbased influenza vaccine

Acquired Marietta vaccine site in PA from Wyeth for cell culture-based influenza vaccine for $\$ 100$ million

Acquired Hungary vaccine company in 2002

Announced plans to double capacity of Dresden Plant, 2005

Broke ground for a new manufacturing facility in Durham, North Carolina, 2004

Broke ground on a new manufacturing facility 2005

Received a \$95-million grant from US Department of Health and Human Services to develop cell culture technology, refit development facility and prepare plans for a manufacturing facility in the US

Invested $\$ 200$ million in PA facility

Wyeth
Haemophilus influenzae type b, pneumococcal disease, triangle cattle vaccines, feline vaccines (combination), canine parvoid/distemper, chicken bursal disease, horse flu, dog giardia, dog Lyme disease, cattle pneumonia, swine mycoplasm, meningococcal meningitis type $\mathrm{C}$
HIV, RSV (subunit and live attenuated nasal), Built a new plant in Ireland pneumococcal (conjugate, 9-valent), HIV (DNA vaccine), meningococcal meningitis type $B$

Source: Company websites and World Health Organization (WHO), http://www.who.int/vaccine_research/documents/en/Status_Table_April05.pdf 
rates among high-risk groups, is another important driver. Savopoulos also expects the most developed Asian states to begin harmonizing their immunization policies with those of the United States, particularly in the wake of the 2003 severe acute respiratory syndrome (SARS) epidemic.

The vaccine industry's big players are less open to innovation at present, Savopoulos says, as the sector went through a phase of exploration with "weird and wonderful" technologies, such as therapeutic vaccines (sometimes referred to as pharmaccines), but with little success. Prevnar demonstrated the commercial feasibility of developing a product with less technical risk. "The big guys seem to be quite happy with what they're doing these days," says Savopoulos.

Even cell culture, which has been proposed as one potential improvement on influenza vaccines production, may not make much of an impact, he argues, as it will still be limited by the same 'dirty' purification processes currently used with egg-based vaccines. Thus far, moreover, recombinant vaccines produced in cells do not appear to be as immunogenic as their egg-based counterparts. "From our research, it's not all it's cracked up to be," he says. He estimates that cell culture-based influenza viruses may take just $15 \%$ of the overall market by 2010 .

The historic underinvestment in vaccine innovation, combined with the focus of the 'big five' players on large-scale product franchises, has provided biotech companies with a plethora of niche opportunities (Tables 3, 4 and 5). According to Alexander von Galbain, CEO of Vienna-based Intercell, the replacement of currently approved vaccines produced using 'obscure' material represents one obvious opportunity. Intercell recently moved its lead product, a vaccine for Japanese encephalitis virus (JEV) infection into pivotal trials. Intercell's candidate product is based on an inactivated virus grown in tissue culture. In contrast, the vaccine currently on the market is extracted from the brains of suckling mice, and, he says, causes a high level of allergic reactions, as well as other side effects. Acambis (Cambridge, MA, USA), is targeting JEV as well, with a live attenuated recombinant vaccine based on a chimeric yellow fever viral vector. It has received FDA approval to initiate a pivotal trial, says CSO Thomas Monath.

Biotech companies with maturing pipelines of vaccine products inevitably face decisions on manufacturing-whether to partner with existing manufacturers, to outsource while retaining product exclusivity (via a contract manufacturing organization $(\mathrm{CMO}))$ or whether to develop an in-house manufacturing capability. However, outsourcing might not be the answer, according to Peter Wulff, CEO of Bavarian Nordic (Kvistgaard, Denmark). "Many CMOs either ask for cash upfront to pay for the investment needed to do the production or they depreciate the cost over the first few production runs so the biotech company has to carry a lot of cost upfront either way," he says. Intercell acquired a 30,000-square-foot facility in Livingston, Scotland, in 2004. Bavarian Nordic, which is vying with Acambis to win a large US government contract for a stockpile of safe smallpox vaccine, based on the modified vaccinia Ankara vector, also acquired a production facility, in Kvistgaard, Denmark, from Orion Pharma (Espoo, Finland).

The US Project BioShield program has been a significant source of recent growth, with US authorities spending hundreds of millions of dollars on stockpiles to protect against anthrax and smallpox (Table 6), as well as smaller investments for new product development (Table 7). These agents were until very recently off-radar for biotech companies, but they now represent important sources

\section{Table 2 Manufacturing processes for vaccines}

\begin{tabular}{ll} 
Vaccine type & Process \\
\hline Attenuated microbial cells & $\begin{array}{l}\text { Growth and purification of microbial cells adapted or engineered to } \\
\text { delete pathogenicity, retaining immunogenicity }\end{array}$ \\
\hline Live microbial vector & $\begin{array}{l}\text { Growth and purification of nonpathogenic microbial cells carrying } \\
\text { added gene for an immunogenic protein }\end{array}$ \\
\hline DNA vaccine & $\begin{array}{l}\text { Extraction and purification of plasmid DNA from bacterial cells con- } \\
\text { taining desired gene in the plasmid }\end{array}$
\end{tabular}

Examples

Mycobacterium tuberculosis vaccine (TICE BCG, Organon Teknika; MycoBax, Aventis Pasteur) Salmonella typhi vaccine (Vivotif, Berna)

Vaccinia and Salmonella typhi being developed to carry multiple antigens; in clinical trials

West Nile virus for horses vaccine (West Nile Innovator, Wyeth)

Salmon infectious hematopoietic necrosis virus vaccine (Apex-IHN, Aqua Health/Novartis)

Recombinant, purified protein, excreted or cell-associated

Conjugated polysaccharides

Live attenuated viruses

Multiple antigen peptide vaccines

Virus-like particles

Live viral vectors
Growth of recombinant bacteria, yeast or cell culture where recombinant protein, cell lysis (for cell-associated proteins), isolation and purification of the protein

Growth of bacterial culture, extraction and purification of capsular polysaccharides, preparation of carrier protein, conjugation to carrier protein

Growth of cells (from cell banks of continuous cells or isolation of primary cells), infection with attenuated virus, isolation and purification of virus

Linking of synthetic peptide antigens to a synthetic backbone (e.g., polylysine)

Growth of cells, infection by virus or recombinant virus producing nonreplicating, noninfectious, particles with intact immunogenic antigens, isolation and purification of the virus-like particles

Growth of cells, infection with genetically engineered replicating nonpathogenic viruses containing added gene of interest, isolation and purification of virus
Bordetella pertussis vaccine (Tripedia, Aventis

Pasteur) Hepatitis B (Recombinvax, Merck)

Haemophilis influenza b vaccine (HibTiter, Wyeth) Streptococcus pneumoniae vaccine (Prevnar, Wyeth) Neisseria meningitidis vaccine (Menjugate, Chiron/ Merck; Neisvac, Baxter/Shire)

Measles, mumps, rubella vaccine (M-M-R II, Merck)

Varicella vaccine (Varivax, Merck)

Yellow fever vaccine (YF-Vax, Aventis Pasteur)

Tuberculosis in clinical trials

HPV, late-stage clinical trial (Gardasel, Merck)

HIV-canary virus (clinical trials)

Source: WHO, http://www.who.int/vaccines-access/quality/contractmanufdb/vaccinetypes_processes.htm and Immunization Action Coalition (St. Paul, MN, USA) 


\section{Box 1 Fresh hope for DNA vaccines}

Injectible DNA-based vaccines received a double boost this year when vaccines against infectious hematopoietic necrosis virus (IHNV) in farmed salmon and against West Nile virus in horses gained approval in Canada and the United States, respectively. Proof-of-concept was first demonstrated in mice more than a decade $\mathrm{ago}^{3}$, but that initial promise did not meet expectations. Similar effects were not seen in human trials, although according to Vijay Samant, CEO of San Diego, California-based DNA vaccine specialist Vical, too much was expected of the technology too quickly. "People ran with this very exciting technology and applied it to very tough targets," he says. Moreover, Merck, a Vical partner, was the only firm to actually subject the technology to an efficacy trial. "Since then, nobody has done a double-blinded infectious disease efficacy trial," he says.

DNA vaccines, based on bacterial plasmids, are an attractive option, because they are precisely defined, can be easily cultivated in recombinant bacteria and appear to be safe. They also contain the CpG motifs characteristic of bacterial DNA, which trigger innate immune responses. Aqua Health of Charlottetown, Prince Edward Island, Canada, the company that gained approval for the salmon vaccine, is a Vical licensee. So too is Harlow, UK-based Merial, an animal health joint venture between Sanofi-Aventis and Merck, which aims to gain approval for a canine melanoma vaccine next year. "We [will then] have three weight categories (small, medium and large animals) in which we have validated this technology," Samant says.

Delivery of sufficient quantities of DNA to elicit a strong immune response has been the biggest obstacle to progress. Several avenues are being explored. Vical uses adjuvants based on cationic lipids to provide a degree of physical protection to the DNA before it encounters a cell membrane. But more high-tech methods are also being developed. PowderMed was spun out of Chiron last year to continue development of a needle-free DNA vaccine delivery method the latter gained when it purchased Oxford, UK-based firm Powderject in 2002. A version of the technology, now called particle-mediated epidermal delivery, has been around for over a decade. It relies on the use of tiny gold particles as carriers of plasmid DNA. These are propelled at near-supersonic speed by pressurized helium gas to penetrate antigenpresenting dendritic cells and keratinocytes beneath the surface of skin. Once inside a cell, the plasmid DNA elutes off from the particle and becomes transcriptionally active. CEO Clive Dix, who had joined PowderJect from GlaxoSmithKline in 2001, says the technology can overcome the delivery problems that have hampered progress with DNA vaccines in humans as it requires only one or two micrograms of DNA to elicit a response. "The people that talk to us [are] slightly skeptical still, I have to say," Dix says. But the approach could offer a rapid and novel approach to manufacturing. "We can build a factory that would have the capacity to produce 150 million doses of this vaccine in three months, from the date when somebody says: 'this is the vaccine to produce'." PowderMed plans to move its lead project, a vaccine for pandemic influenza, into human trials next year.

Intramuscular electroporation is also gaining some ground, after the acquisition earlier this year of a Norwegian pioneer in the area, Inovio, by Genetronics Biomedical. The merged entity, Inovio Biomedical, of San Diego, is focusing on oncology but has licensed DNA vaccine applications to partners, including Chiron and Vical. Chiron's Jeffrey UImer says it can increase the efficiency with which DNA is taken up by target cells by 100fold, although the technology still has to prove itself in terms of safety, tolerability and practicability. PowderMed's technology can now be manufactured as a disposable device. "One would imagine, with technological developments, one could apply the same principle to electroporation, says UImer."

of revenue, as well as $\mathrm{R} \& \mathrm{D}$ funding for firms such as VaxGen (Brisbane, CA), Acambis and Bavarian Nordic.

And because the overall market is still relatively small, individual product successes have a substantial impact on its topline. Wyeth's Prevnar, a pediatric vaccine against the causative agent of invasive pneumococcal disease, Streptococcus pneumoniae, does not represent any major technological breakthrough,
Savopoulos says. It contains saccharides derived from the capsular antigens of seven common S. pneumoniae serotypes, each individually conjugated to a nontoxic variant of the highly immunogenic diphtheria toxin, isolated from a Corynebacterium diphtheriae strain. Yet it represents the kind of commercial breakthrough that has validated the broader vaccine space. First approved by the FDA in February 2000, it clocked up revenues of $\$ 1.1$ 
Table 3 Selected biotech companies dedicated to the research, development and manufacture of prophylactic vaccines

Company (location)

Acambis (Cambridge, UK and Cambridge, MA, USA)

http://www.acambis.com/

Alphavax (Research Triangle

Park, NC, USA)

home/

Bavarian Nordic

http://www. bavarian-nordic. $\mathrm{com} /$

Berna Biotech

http://www.bernabiotech.com/

$A$ and hepatitis B. Under development:

hepatitis $B$ (phase 3 ), yellow fever (phase

3), Pseudomonas aeruginosa (phase 3 )

Anthrax

Bioport (Lansing, MI, USA)

a subsidiary of Emergent

BioSolutions (Gaitherburg,

MD, USA)

http://www.bioport.com/

default.asp

\section{Cambridge Biostability}

(Cambridge, UK)

http://www.biostability.com/

CSL (Parkville, Australia)

DynPort Vaccine Company

(Frederick, MD, USA)

http://www.csc.com/mms/ dvc/en/

ID Biomedical (Vancouver,

$\mathrm{BC})$

http://www.idbiomed.com/

Intercell (Vienna)

http://www.intercell.com/

Iomai (Gaithersburg,

Maryland, USA)

http://www.iomai.com/

Nobilon (Boxmeer, The

Netherlands) part of the Akzo

Nobel Pharma Group

http://www.nobilonvaccines.

com/

VaxGen (Brisbane, CA, USA)

http://www.vaxgen.com/

keted), yellow fever, Japanese encepha-

litis, West Nile, Dengue, Clostridium

difficile

HIV (phase 1), cytomegalovirus, influ-

Marburg virus, viral encephalitis and

botulinum toxins

Smallpox, HIV, Japanese encephalitis, Dengue and measles
Enterotoxic Escherichia coli

Diphtheria with tetanus vaccine, (marketed), Q Vax (Coxiella burnetii vaccine, marketed) Tet-Tox (Tetanus vaccine, marketed) Fluvax (influenza vaccine, egg-based, trivalent, marketed) Plagues vaccine (Yersinia pestis marketed); HPV (Phase 3, licensed to Merck) HCV (Phase 2, licensed to Chiron)

Botulism, plague, tularemia and Venezuelan equine encephalitis

Influenza, Neisseria meningitides, pneumococcal disease and group A streptococcus infections

Japanese encephalitis virus (phase 3) and hepatitis C (phase 2), streptococcal hospital-acquired infections and tuberculosis

Transcutaneous vaccination two influenza vaccines (phases 1 and 2), traveler's diarrhea (phase 2) and anthrax (phase 1)

Influenza, traveler's diarrhea, sexually transmitted diseases

Vaccine focus (development phase, if any) Technology

Business strategy

Vaccinia vaccines, live viral vectors

Development and manufacture of vaccines attenuated by recombinant technology Partnered with Baxter Healthcare for distribuand vaccines using inactivated bacte- tion rial toxins

Live viral vectors based on alphavirus eplicon expressing viral or bacterial antigens

Live viral modified vaccinia Ankara (MVA) vectors g viral capsid components)

or antigen presentation, live virus/

bacteria attenuated by recombinant technology as well as a recombinant subunit vaccine

Aluminum hydroxide-adsorbed cellfree vaccine prepared from Bacillus anthracis strain V770-NP1-R

Development of vaccine delivery systems. Some company funded, others grant funded, others partner funded. Partnered with Wyeth for herpes simplex virus, HPV, flu and respiratory syncytial virus

Development and manufacture vaccines. Partnered with GSK for smallpox, IDM Pharma for HIV vaccines, Impfstoffwerk Dessau-Tornau $\mathrm{GmbH}$ for manufacturing

Development and manufacture of vaccines. Partnered with Corixa, Orphan Europe, Chiron and Solvay

Manufacture and supply US government stockpile of only FDA-approved anthrax vaccine

Technology for stabilizing vaccines in sugar glass and suspension in fluorocarbon liquids

Iscomatrix adjuvant, Virus-like particles

tion partner for Merck \& Chiron
Vaccine formulation and delivery. Partnered with Acambis

icensed vaccines to Merck \& Chiron, distribu-
Live-attenuated vaccines, recombinant Subcontracts vaccine programs to research censubunit vaccines and vaccine delivery ters and companies. Partnered with Avant and systems

Combination nasal delivery system and adjuvant made from nanospheres of bacterial proteins; recombinant subunit vaccines

Recombinant protein vaccines and synthetic adjuvant combining an antimicrobial peptide, and an immunostimulant oligodeoxynucleotide

Needle-free, transcutaneous vaccination using cholera toxin or heat-labile enterotoxin as adjuvants.

Biofermentation expertise Anthrax, smallpox and bacterial meningitis
Baxter and The National Institute of Allergy and Infectious Diseases

\section{Development of vaccines}

Acquired by GSK as antigen/epitope identification/validation services. Partnered with Merck

Development of vaccines

Contract manufacture of vaccines. Works with other Akzo companies: Intervet (animal vaccines), Organon (human pharmaceutical production). Partnered with BioDiem for flu vaccine

Development and manufacture of biodefense vaccines with facilities in California and South Korea. Partnered with Celltrion Incheon (South Korea) to build production facilities
Vaccines and other immunotherapies as well
Recombinant subunit vaccines with alum-adjuvant as well as vaccinia vaccine billion in 2004, despite production problems, and it racked up a further $\$ 714$ million during the first half of 2005. Efficient prelaunch marketing activity, which included gaining the backing of the key influencers in the area, enabled the company to set a relatively high price for the product, thus ensuring its commercial success, says Savopoulos, "it basically comes down to effective prioritization of your research programs and putting your money behind the right horse."

GlaxoSmithKline and Merck both want to follow suit. Each is developing an HPV vaccine, based on L1 virus-like particles, to protect against cervical cancer. Merck's biologic license 


\section{FEATURE}

application filing for its product, Gardasil, which protects against two HPV strains implicated in cervical cancer and two more implicated in the development of genital warts, is imminent. Sanofi Pasteur MSD, its European joint venture with Sanofi Pasteur, is due to file in Europe shortly afterwards. GlaxoSmithKline, which developed its rival product, Cervarix, in collaboration with MedImmune (Gaithersburg, MD, USA), aims to file in Europe in 2006 but has yet to disclose the time frame for a US filing. Although Merck may be first to market with its product, which it codeveloped with CSL (Parkeville, Australia), GlaxoSmithKline stands to gain a royalty stream from this franchise as well, following the settlement of a patent dispute between the two companies earlier this year. Vaccines now represent an important element of GlaxoSmithKline's growth strategy, and were, uncharacteristically, the main focus of a pipeline update during the summer.

\section{Table 4 Selected public biotech companies with a business interest in prophylactic vaccine development}

\section{Company (location)}

Avant Immunotherapies

(Needham, MA, USA)

http://www.avantimmune.com/
Prophylactic vaccine focus (development phase, if any)

Rotavirus (marketed by GSK), HIV (phase 1), anthrax (phase 1) Salmonella vaccine for chickens (marketed) and plague

H5N1 influenza and SARS

Antigen Express (Worcester, MA, USA), a wholly owned subsidiary of Generex Biotechnology (Toronto) http://www.antigenexpress.com

Crucell (Leiden, The Netherlands) http://www.crucell.com/

Dong Shin Pharma (Seoul, Korea) http://www.dong-shin.com/

EpImmune (San Diego, CA, USA)

http://www.epimmune.com/

templates/epmn.cfm

Henderson Morley

(Birmingham, UK)

http://www.henderson-morley.com

Innogenetics (Ghent, Belgium)

http://www.innogenetics.com

MedImmune (Princeton, NJ, USA) http://www.medimmune.com/

Nabi Biopharmaceuticals

(Boca Raton, FL, USA)

http://www.nabi.com/

Sinovac, Beijing,

www.sinovac.com

Solvay Pharmaceuticals (Brussels) Influenza

http://www.solvaypharmaceuticals. com

United Biomedical

(Hauppauge, NY, USA)

http://www.unitedbiomedical.com

Vical (San Diego, CA, USA)

http://www.vical.com/

Ebola, influenza, malaria, and West Nile virus

Influenza, Japanese encephalitis, rubella

HIV (phase 1/2)

Genital herpes

Hepatitis C (phase 2), hepatitis B (phase 1) and genital warts/cervica dysplasia due to human papillomavirus

Influenza (FluMist; marketed), infectious mononucleosis (phase 2), pneumococcal disease (phase 1), respiratory disease due to respiratory syncytial virus (phase 1 ),

Hospital-acquired staphylococci and enterococci infections (phase 1 , 2/phase 3 completed)

Hepatitis A,B (marketed), flu, SARS (phase 1)

HIV and foot and mouth disease
Anthrax (phase 1), infectious mononucleosis (phase 1), malaria (phase 1/2), Ebola (phase 1), West Nile (phase 1), SARS (phase 1), HIV (phase 1 ), hepatitis $B$, hepatitis $C$ and $\mathrm{H} 5 \mathrm{~N} 1$ influenza li-key protein fusions to viral or bacterial epitopes to facilitate MHC class II presentation. Ii suppression platform to augment DNA vaccines

Inactivated split and whole viral vaccines. Replication-deficient adenovirus vectors expressing microbial antigens. Inactivated whole virus or inactivated viral subunit vaccines

Computer algorithms for epitope identification and selection together with proprietary adjuvant peptide sequence (PADRE)

'Intracellular' vaccines based on extracts of infected cells from which herpes simplex virus type 2 DNA and particles have been removed. Previra DNA replication enveloped virus vaccines

Recombinant subunit protein vaccine for hepatitis $C$ and recombinant polyepitope vaccines for hepatitis $B, C$ and human papillomavirus

Cold-adapted live influenza virus vaccine, chimeric viral vaccine expressing recombinant proteins from viral pathogens, and recombinant vaccine against Streptococcus pneumoniae

Polysaccharide conjugate vaccines against staphylococci and enterococci

Inactivated whole virus or inactivated viral subunit vaccine

Recombinant subunit protein vaccines for influenza produced in Madine Darby canine kidney cell culture

Synthetic peptide-based vaccines

DNA vaccines delivered using cationic liposomes
Business strategy

Vaccines and other immunotherapeutics. Partnered with Pfizer (food safety), GlaxoSmithKline (rotavirus), the International Vaccine Institute, Dynport and Lohmann Animal Health International. Opening manufacturing facility in Fall River, Massachusetts

Developing a broad range of vaccines and therapeutics based on li family of MHC-regulating proteins. Partnering with Chinese Academy of Sciences (SARS)

Vaccines and antibody products. Partnered with Chiron, MedImmune, Merck, Sanofi Pasteur and Vaxin

Vaccines, biopharmaceuticals and nutritional products

Therapeutic vaccines in infectious disease and cancer. Partnered with Innogenetics

Anti-viral treatments and diagnostics and herpes simplex type 2 vaccines

Therapeutic vaccines for infectious disease as well as diagnostics, genetic testing and biomanufacture. Partnered with Bayer Diagnostics, Rhein Biotech, Roche Diagnostics, Abbott Laboratories, EpImmune PamGene, Third Wave Technologies

Vaccines and antibody therapeutics in oncology, infectious diseases and immunology. Partnered with ViroNovative and Wyeth (co-promoter of FluMist) and GlaxoSmithKline

Vaccines and monoclonal antibodies against infectious disease. Partnered with Cambrex for manufacturing. Building own manufacturing facilities

Research, development, commercialization and sales of human vaccines for infectious diseases

Vaccines, pharmaceuticals, chemicals and even plastics. Partnered in vaccines with Berna Biotech

Peptide immunogens for use in vaccines and immunotherapies in human and animal health and contract manufacturing services

DNA vaccines and gene therapies. Contract manufacturer of DNA plasmids. Partnered with Merck and National Institutes of Health for human health and Aqua Health and Merial for veterinary products 
Table 5 Selected private biotech companies with a business interest in prophylactic vaccine development

Company (location)

Antigenics (New York)

http://www.antigenics.com/

Aridis Pharmaceuticals (Sunnyvale, CA, USA)

Shigella and rotavirus

Genital herpes (phase 1)

AuRx (Glen Burnie, MD, USA)

http://www.aurx.com/index.htm

Avecia Biotechnology (Manchester, UK)

http://www.avecia.com/biotech/default.htm

Bharat Biotech (Hyderabad, India)

http://www.bharatbiotech.com/

BioVirus Research (Reno, NV, USA)

Cerus (Concord, CA, USA)

http://www.cerus.com

Emergent Biosolutions (Gaithersburg, MD, USA)

http://www.ebsi.com/home.asp

Plague and anthrax typhoid (launched)

Genital herpes

Anthrax
Epivax (Providence, RI, USA)

http://epivax.com/

GenPhar (Mt. Pleasant, SC, USA)

http://www.genphar.com/

Hawaii Biotech (Aiea, HI, USA)

http://www.hibiotech.com

Novavax (Malvern, PA, USA)

http://www.novavax.com

Oxxon Therapeutics (Oxford, UK)

http://www.oxti.com

PowderMed (Oxford, UK)

http://www. powdermed.com/

Protein Sciences (Meriden, CT, USA)

http://www.proteinsciences.com/
Prophylactic vaccine focus

(if any)

Genital herpes (phase 1/2)

Hepatitis B (launched) and

Anthrax, Chlamydia trachomatis, Helicobacter pylori and influenza

Aluminum hydroxide-adsorbed cellfree vaccine prepared from Bacillus anthracis strain V770-NP1-R

Helicobacter pylori ulcers, tularemia and smallpox

HIV (phase 1/2)

Influenza, West Nile virus, and dengue fever

HIV, influenza, hepatitis $E$ and SARS

Malaria (phase 2), tuberculosis

(phase 1) and HIV (phase 2)

Technology

Antigen from herpes simplex virus type 2 vaccine complexed with heat-shock protein

Dehydration technology and addition of stabilizers that enhance vaccine half-life

Herpes simplex virus type 2 vaccine attenuated by recombinant technology.

Oligonucleotide synthesis and biologic manufacture

Recombinant hepatitis B virus surface antigen vaccine and purified Salmonella typhi Vi capsular polysaccharide

A computational platform for designing synthetic peptide vaccines

Expression of antigens on killed but metabolically active strains of Listeria monocytogenes

A computational platform for identifying T-cell epitopes in peptide sequences

Adenovirus vectors for antigen delivery

Recombinant protein vaccines Expression in insect cells of virus-
particle technology for expressing antigens

Prime-boost vaccines based on recombinant modified vaccinia virus, Ankara-expressing antigens

DNA-based vaccine delivered by gene gun

1 ), genital herpes (phase 1), genital warts and hepatitis $B$ Influenza (phase 3 ) and SARS

Recombinant subunit protein vaccine produced in baculovirus expression system

Live viral vaccines attenuated by recombinant technology
Business strategy

Developing immunotherapies for cancer, infectious diseases, autoimmune degenerative disorders. Partnered with GlaxoSmithKline, Wyeth, Aventis Pasteur, Progenics, Elan

Developing new vaccine formulations, processing and delivery approaches. Partnered with the $\mathrm{NIH}$

Focused on vaccines and therapies for herpes simplex type 2

Contract manufacturing services for DNA and protein vaccines

Vaccines, biopharmaceuticals and biomanufacturing. Partnered with Mvelaphanda (S. African gold and diamond company)

Focused on vaccines and therapies for herpes simplex virus type 2. Partnered with Tekron (Ft. Lauderdale, FL)

Vaccines and blood safety products for infectious disease and cancer. Partnered with MedImmune, Baxter Healthcare, BioOne

Vaccines and related products. BioPort manufacturing arm Antex Biologics, research arm acquired UK-based Microscience 2005. Expanded manufacturing capacity in 2004 with purchase of new facility in Frederick, Maryland

Research services for vaccine development

Viral diagnostics, vaccines, cancer therapies. Partnered with NIH for testing HIV vaccine in monkeys and USAMIRD for Marburg

Vaccines and small molecules. Partnered with Cobra for manufacture of dengue and West Nile vaccine

Vaccines, drug delivery and biologics. Partnered with National Institute of Allergy and Infectious Diseases (NIAID), Walter Reed Army Institute for Research and GlaxoSmithKline

Vaccines and other immunotherapies for infectious disease and cancer. Partnered with Wellcome Trust, Medical Research Council and Malaria Vaccine Initiative

DNA vaccines. Partnered with GlaxoSmithKline (HIV)

Antigen and protein reagents, vaccines $R \& D$ and contract manufacturing services. Contract with NIAID to produce SARS S-protein subunit vaccine

Vaccines and biopharmaceuticals 
Table 6 Selected vaccine supply contracts for project BioShield

\begin{tabular}{|c|c|c|c|c|}
\hline Company & Product & Pathogen & Award (millions) & Date \\
\hline \multirow[t]{3}{*}{ Acambis } & MVA3000 & Smallpox & $\$ 76.3$ & $10 / 7 / 2004$ \\
\hline & \multirow{2}{*}{$\begin{array}{l}\text { Modified vaccinia Ankara (MVA) attenuate } \\
\text { vaccine }\end{array}$} & Smallpox & $\$ 10$ & $02 / 25 / 2003$ \\
\hline & & Smallpox & $\$ 428$ & $11 / 28 / 2001^{\mathrm{a}}$ \\
\hline \multirow[t]{2}{*}{ Bavarian Nordic } & \multirow[t]{2}{*}{ Imvamune MVA } & Smallpox & $\$ 100$ & $10 / 07 / 2004$ \\
\hline & & Smallpox & $\$ 23^{b}$ & 09/25/2003 \\
\hline \multirow[t]{5}{*}{ DynaPort } & Vaccine development, pilot production & Francisella tularemia & $\$ 35.1$ & $10 / 05 / 2005$ \\
\hline & Vaccine development & \multirow{4}{*}{$\begin{array}{l}\text { Francisella tularemia, Clostridium } \\
\text { botulinum, Venezuelan equine } \\
\text { encephalitis virus } \\
\text { Clostridium botulinum } \\
\text { Francisella tularemia }\end{array}$} & $\$ 19.7$ & $12 / 07 / 2004$ \\
\hline & Hepatavalent vaccine development & & $\$ 11$ & 09/04/2003 \\
\hline & Live attenuated vaccine & & $\$ 4.6$ & $10 / 07 / 2004$ \\
\hline & & & & \\
\hline
\end{tabular}

Source: US Department of Health \& Human Services. ${ }^{a}$ Original order for 209 million doses cut to 182.5 million doses. ${ }^{b}$ Grants shared by two companies, individual grant not disclosed.

Table 7 Biotech companies with Bioshield vaccine projects

\begin{tabular}{|c|c|}
\hline Company (location) & Project (clinical development) \\
\hline Aridis Pharmaceuticals & Live, oral heat stable Salmonella typhi vaccine \\
\hline Avant Immunotherapies & Bacterial, viral, biodefense vaccines \\
\hline Avecia Biotechnology & Recombinant plague and anthrax protein vaccines \\
\hline Cerus & Anthrax \\
\hline Curalab (Stoughton, MA, USA) & Universal influenza vaccine cell line \\
\hline Epivax & Tularemia epitope vaccine and smallpox vaccine from Immunome \\
\hline Hawaii Biotech & Recombinant subunit influenza vaccine \\
\hline Intercell & Japanese encephalitis virus (phase 3 ) \\
\hline Iomai & Transcutaneous vaccination influenza (phase 2), traveler's diarrhea (phase 2), anthrax (phase 1) and influenza (phase 1) \\
\hline L2 Diagnostics (New Haven, CT, USA) & Recombinant West Nile subunit vaccine \\
\hline Medarex (Princeton, NJ, USA) & Improved targeted anthrax vaccine \\
\hline Novavax & Virus-like particle vaccines for influenza, hepatitis $\mathrm{E}$ and SARS \\
\hline Sciogen & Recombinant influenza vaccine \\
\hline Technovan & Virus-like particles as vaccines \\
\hline Vical & Anthrax, infectious mononucleosis, malaria, Ebola, West Nile, SARS, HIV, hepatitis B, hepatitis C, H5N1 influenza \\
\hline
\end{tabular}

Over the coming years, it also aims to launch Streptorix, (a ten-valent $S$. pneumoniae conjugated vaccine) a competitor to Prevnar that will protect against ten $S$. pneumoniae serotypes, and Rotarix, an oral, live attenuated vaccine, which prevents rotavirus infection, among other products.

\section{New mind-set}

There is still a tension, however, between what the market-or regulators-will accept and what modern molecular biology can deliver. The pace of innovation in the vaccine industry has been slow, partly because of the inherent difficulty of developing effective new vaccines and partly because of the inertia engendered by an historically stagnant market. Putative blockbusters notwithstanding, much of the recent product development activity conducted by the main vaccine manufacturers has consisted of adding incremental improvements and enhancements to their existing portfolios $^{2}$. Many new product approvals consist of combinations of vaccines that are already on the market. From a commercial perspective combination vaccines have an easier path because a precedent has been already set for their 'need' in the marketplace. From a regulatory perspective the combo vaccine still has to prove the same levels of afforded immunogenicity as the single components. Genuinely novel products that address new antigens or pathogens against which there is no current protection are rare.

"I think the problem we all face is the people in the vaccine industry have started from a very low technological base," says Clive Dix, CEO of Oxford, UK-based PowderMed. A "cheap and cheerful" mentality still exists, he says, which requires vaccines to be low-tech and low-cost.

Nevertheless, novel ideas and novel approaches are beginning to filter through. But there is also a considerable backlog of work to be done on simply hauling ineffective or limited vaccines, or those produced via crude production methods, into the molecular biology era.

1. Scherer F.M. American Anti-Trust Institute Working Paper 04-03 29 (American Anti-Trust Institute Washington, DC, October 2004). http://www.antitrustinstitute.org/recent2/351.pdf

2. Datamonitor. Commercial Perspectives: Vaccines (Datamonitor, London, January 2004).

3. Ulmer J.B. et al, Heterologous protection against influenza by infection of DNA encoding a viral protein. Science 259,1691-1692 (1993). 